\title{
Cued visual attention does not distinguish between occluded and occluding objects
}

\author{
CRAIG HAIMSON and MARLENE BEHRMANN \\ Carnegie Mellon University and the Center for the Neural Basis of Cognition, \\ Pittsburgh, Pennsylvania
}

\begin{abstract}
Does visual attention spread from the cued end of an occluded object to locations occupied by inferred portions of that object? We investigated this question by using a probe detection paradigm with two-dimensional (2-D) displays of occluded objects. Probes could appear in occluded or nonoccluded locations on either a cued or noncued object. Participants responded faster to probes appearing within the region of space occupied by the cued object. This was true not only when the probe appeared in positions separated from the cued location by an occluder (as demonstrated by Moore, Yantis, \& Vaughan, 1998), but also when it appeared in positions on the occluder itself. Thus, results suggest that cued facilitation spreads to regions of noncued occluding objects that overlap cued occluded objects in 2-D space.
\end{abstract}

Because the visual system receives far more information than it can interpret effectively at any given moment, it has developed processes of selection that increase the accessibility of certain portions of input at the expense of others. How the visual system identifies a portion of to-beselected input has been the subject of considerable debate (e.g., Duncan, 1984; Kramer, Weber, \& Watson, 1997; Posner, Snyder, \& Davidson, 1980; Vecera \& Farah, 1994). Nevertheless, several recent studies have indicated that both perceptual organization and spatial location can influence visual selection (Egly, Driver, \& Rafal, 1994; Kramer \& Jacobson, 1991; Lavie \& Driver, 1996; Vecera \& Farah, 1994). The work we describe here provides further evidence for the interaction of space-based and objectbased factors in visual attention.

In this paper, we are concerned with how space-based attention (the enhancement of information processing at specific locations; e.g., Posner et al., 1980) operates on visual objects that are partially occluded by other objects appearing in front of them. In particular, we are interested in how space-based attention acts on those regions of input in which occluding and occluded objects overlap. Such a region presents somewhat of a paradox to the visual system, since it subsumes a set of locations that "belongs" in some sense to both objects. This situation

We thank Roberta Klatzky, David Plaut, and three anonymous reviewers for helpful comments on this manuscript. We also thank Raymond Klein and Peter McCormick for comments on an earlier version of this paper, as well as Gordon Baylis and Richard Zemel for useful discussions concerning this research. This research was supported by NIMH Grant MH54776-06 to M.B. and a National Defense Science and Engineering Graduate Fellowship to C.H. Correspondence concerning this article should be addressed to C. Haimson, Department of Psychology, Baker Hall 342-C, Carnegie Mellon University, 5000 Forbes Ave., Pittsburgh, PA 15213 (e-mail: chaimson@ andrew.cmu.edu). prompts us to ask the following question: Can the visual system attend to the inferred portions of an occluded object without, at the same time, attending to the corresponding region of the occluding object in front of it? To exclude this region from the focus of attention would be contrary to the goals of an attentional system, which attempts to select the entire region of input occupied by the occluded object. However, amodal completion (the inferring of occluded portions of an object) requires that the visible portions of an occluded object be considered as separate from the occluder lying in front of the invisible region that joins them. To include the occluder in the focus of attention would seem to counteract this computational demand.

We addressed this question by using Egly et al.'s (1994) version of the standard cued probe detection task (e.g., Posner et al., 1980). Numerous results obtained with the standard task indicate that participants are quicker and more accurate in responding to probes presented at or near a cued location (Henderson, 1991; Posner et al., 1980). This cue validity effect (so-called because enhancement occurs when cues validly predict target location) is generally attributed to the allocation of space-based attention to the cued area (Posner et al., 1980). However, Egly et al. showed that a cue presented in one region of an object facilitated probe detection in other noncued regions within the object as well. Their displays contained two rectangles in which the distance between opposite ends of a single rectangle was equal to that between the same ends of different rectangles (see Figure 1A for an example of their stimuli). On each trial one of the ends of one of the rectangles brightened briefly, after which a target square appeared at one of the rectangle ends. Although targets were detected most rapidly at previously cued locations, targets at the noncued ends of cued rectangles were still detected faster than those appearing within noncued rec- 

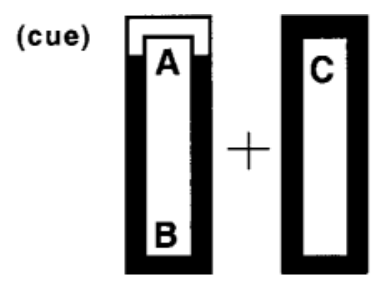

Egly, Driver, \& Rafal (1994)

RTs: $\mathrm{A}<\mathrm{B}<\mathrm{C}$

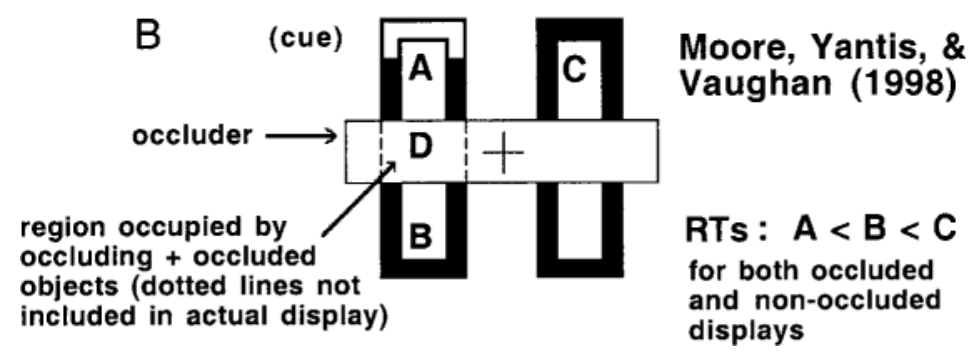

Figure 1. Sample stimuli used by (A) Egly, Driver, and Rafal (1994) and (B) Moore, Yantis, and Vaughan (1998). Hypothetical region of space occupied by both the cued rectangle and central occluder.

tangles. For example, if location A in Figure 1A was cued, probe detection would be fastest at location $\mathrm{A}$ (cued location), slower at location B (within-object location), and slowest at location $\mathrm{C}$ (between-object location). Egly et al. attributed this within-object benefit to the allocation of an object-based attention.

Nevertheless, although Egly et al.'s (1994) results clearly imply that cuing directs attention to regions of input associated with entire objects, it is probable that the attention it directs is still spatial in nature. Vecera (1994) demonstrated that reaction times (RTs) to invalidly cued probes appearing in noncued rectangles (as in location $\mathrm{C}$ in Figure 1A) decreased as the distance separating the two rectangles decreased. This result indicated that the paradigm was still susceptible to the same proximity manipulations as observed in other cued probe detection studies (e.g., Henderson, 1991; Henderson \& Macquistan, 1993). Moreover, Egly et al. reported that patients with left parietal lobe damage were unusually slow at detecting probes appearing on their contralesional side in noncued objects, suggesting that the effect is at least partly mediated by left hemispheric parietal representations. Evidence from neuropsychology (e.g., Posner, Walker, Friedrich, \& Rafal, 1984), neurophysiology (Gottlieb, Kusunoki, \& Goldberg, 1998; Steinmetz \& Constantinidis, 1995), and neuroimaging (Corbetta, Kincade, Ollinger, McAvoy, \& Shulman, 2000; Corbetta, Miezin, Dobmeyer, Shulman, \& Petersen, 1991; Corbetta, Miezin, Shulman, \& Petersen, 1993) has led theorists to suggest that spatial representations in parietal cortex and other areas in the dorsal visual stream (Ungerleider \& Mishkin, 1982) are involved in the mediation of space-based attention (e.g., Desimone \& Duncan, 1995; Posner \& Petersen, 1990).

Vecera (1994) suggested a model in which object representations identify regions of input associated with the same perceptual configurations (e.g., objects or collections of objects forming salient groups), whereas spatial representations prime processing of information appearing in these locations (i.e., space-based attention is allocated to these positions); other researchers have offered similar proposals for interactive visual attention networks (e.g., Behrmann \& Haimson, 1999; Desimone \& Duncan, 1995; Farah, 1990; Humphreys \& Riddoch, 1993; Phaf, van der Heijden, \& Hudson, 1990). Thus, by virtue of perceptual organization, uncued portions of cued objects become associated with cued portions, allowing spacebased attention to facilitate processing in locations occupied by both the latter and the former. It may actually be that attention spreads from cued to noncued locations over time (e.g., Avrahami, 1999; Neely, Dagenbach, Thompson, \& Carr, 1998; Saiki, 1997), following the contour of the object in a manner similar to the curve tracing operation described by Jolicœur and colleagues (Jolicœur, Ullman, \& Mackay, 1986; McCormick \& Jolicœur, 1992). However, the parallel between attention spreading and curve tracing should not be over-emphasized; although attention may spread along the contour of an object following cuing, it is not clear that its purpose is to determine whether all points along the contour are connected, as it is with Jolicœur et al.'s curve tracing operator.

Moore, Yantis, and Vaughan (1998) recently demonstrated that attention spread from cued to noncued ends of occluded objects in three-dimensional (3-D) displays. In Experiment 1, they presented participants with rectangle displays similar to those of Egly et al. (1994). However, in critical blocks, the centers of the two rectangles were occluded by a third rectangle presented in the center of the display and oriented perpendicular to the other two (see Figure 1B for an example of their stimuli). Moore et al. presented stimuli under stereoscopic conditions in order 
to create the impression that the occluded rectangles and occluding rectangle appeared on two different depth planes, with the occluding rectangle closer to the viewer; occluding and occluded objects occupied the same twodimensional (2-D) region of space but different 3-D regions of space. The participants were quickest to report the identity of a target when it appeared at the cued end of the cued rectangle, and they were faster at identifying an invalidly cued target when it appeared at the noncued end of the cued rectangle (Figure 1B, location B) than at either end of the noncued rectangle (e.g., Figure 1B, location C). Moreover, results were identical under both occluded and nonoccluded conditions. Thus, cued attention appeared to spread to portions of input containing visible parts of occluded objects.

We sought to determine whether attention would also spread to portions of input in which a cued occluded object is hidden. As we noted, such a region (as in the area enclosed by dotted lines in Figure 1B) should logically be assigned to the occluding object that appears in front. In order for space-based attention to avoid selecting part of this noncued object, it would need to "pass over" the occluding region, thereby dividing its focus between the visible portions of the cued object behind it. There is some evidence that participants may allocate attention to multiple noncontiguous locations simultaneously (e.g., Castiello \& Umiltà, 1992; Cave \& Pashler, 1995; Kramer \& Hahn, 1995; Wright, 1994; for conflicting evidence, see McCormick, Klein, \& Johnston, 1998). However, an occluded object appears to occupy a single set of locations encompassing both its visible and inferred portions, and it is not clear that space-based attention can be split between noncontiguous locations subsumed by the same object. Davis and Driver (1997a, 1997b) did demonstrate that attention may exclude an occluder when the object behind it is cued or selected in 3-D stereoscopic displays, but these results may indicate only that attention is depthor surface-specific (e.g., Atchley, Kramer, Andersen, \& Theeuwes, 1997; Downing \& Pinker, 1985; He \& Nakayama, 1995). Cuing could have directed attention to a single set of locations in 3-D space that included inferred portions of the occluded objects lying behind the occluder.

As a result, we used 2-D displays of overlapping objects containing only pictorial cues for amodal completion. Even though pictorial cues allow participants to infer the existence of the hidden portions of occluded figures, they should not override other cues, such as binoculardisparity, that indicate that occluded and occluding objects lie along the same flat plane in 3-D space (i.e., the computer monitor). Thus, an occluding object should appear to occupy the same locations as the occluded object in the region in which they overlap. If space-based attention is then allocated to all of the locations occupied by the occluded object, the occluding region will receive cued facilitation even though it "belongs" to a different object than the one whose locations are actually being selected. We hypothesized that cuing an occluded object would facilitate the detection of a probe appearing anywhere within the set of lo- cations that the object subsumed, including both shared (as in location D in Figure 1B) and nonshared (as in location B in Figure 1B) positions.

\section{METHOD}

\section{Participants}

Twenty-nine undergraduates (16 male and 13 female) at Carnegie Mellon University participated in this experiment in partial fulfillment of a course requirement. All were between the ages of 18 and 24 , and all had normal or corrected-to-normal vision.

\section{Stimuli}

Sample stimulus displays are shown in Figure 2A. Each display contained two pairs of crossed "hockey sticks" configured around a black central fixation cross $\left(0.3^{\circ} \times 0.3^{\circ}\right)$ on a lavender background. Each hockey stick consisted of a short rectangle $\left(0.6^{\circ} \times 1.1^{\circ}\right)$ and a long rectangle $\left(0.6^{\circ} \times 2.3^{\circ}\right)$ joined together in an obtuse angle facing away from the center of the display. The hockey sticks in each pair crossed near the points at which each short rectangle met its long rectangle. The two pairs formed mirror-image $\mathrm{V}$ configurations on either side of the fixation cross, with crossed ends situated furthest from the center of the display and aligned along either the horizontal or vertical meridian (hereafter referred to as either horizontal or vertical displays). Each hockey stick also intersected its mirror image in the other pair, forming acute angles at points $0.6^{\circ}$ from the tips of the long rectangles; note that at every point where two hockey sticks crossed, the stick in front partially occluded the stick behind it. Entire displays subtended areas of $3.4^{\circ} \times 4.6^{\circ}$. Each pair contained one hockey stick colored dark yellow with a red border and one colored light blue with a dark blue border; color schemes alternated so that intersecting hockey sticks from different pairs had opposite coloring.

Ten observers naive to the goals of the experiment provided their phenomenological impressions of the displays. All 10 reported that displays contained four bent rectangles intertwined, with each rectangle appearing either above or below two other rectangles. Their descriptions agreed with those of the participants in the actual experiment, as well. These reports suggest that displays did encourage amodal completion of occluded objects so that two disconnected ends appeared to be connected behind the object that appeared in front of them.

There were two sets of two displays at each orientation, for a total of eight different versions of the stimulus. In one set, the yellow hockey stick in each pair appeared on top of the blue one at the point at which they crossed; in the other set, the blue hockey stick appeared on top. In each set, a given pair of hockey sticks appeared once in front of the other pair at the points at which their members intersected and once behind them. The two stimulus sets for horizontal displays are shown in Figures 2B-2E.

As described above, each set of stimuli contained two versions of displays in which hockey sticks of a given color appeared in front at within-pair crossing points. In the set of displays depicted in Figures $2 \mathrm{~B}$ and $2 \mathrm{C}$, the yellow hockey sticks are in front. Note that, in Figure $2 \mathrm{~B}$, the hockey sticks in the pair to the left of fixation are in front at the point at which they intersect the hockey sticks in the pair to the right of fixation. If a cue were presented on the yellow stick in the left pair in this display, it would appear on a nonoccluded object. In contrast, if it were presented on the yellow stick in the right pair, it would appear on an occluded object. As shown in Figure 2C, the opposite is true for the other display in this stimulus set. Thus, both nonoccluded and occluded conditions were represented across the set of displays. Note that, unlike in Moore et al. (1998), displays in this experiment did not contain an occluder object that could never be cued. Instead, every object could be cued, and every object could serve as an occluder. 


\section{Cued Rectangle on Top Cued Rectangle on Bottom}

A
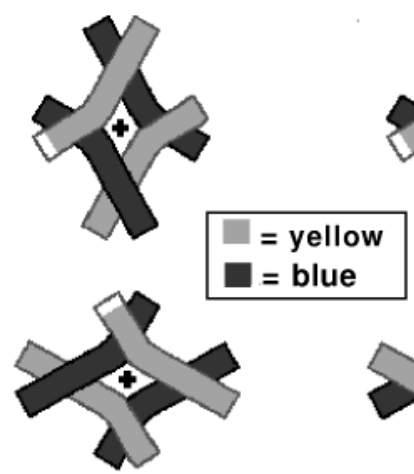

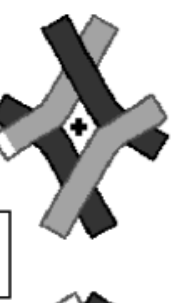

Horizontal

Cued End

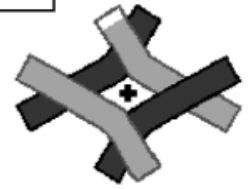

Vertical

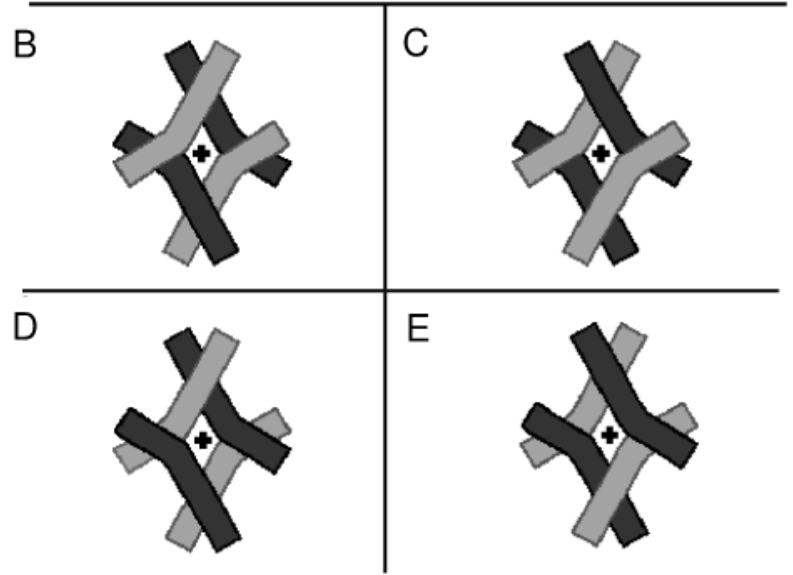

Figure 2. (A) Sample stimuli. (B and C) One horizontal display set. (D and E) Other horizontal display set.

During cuing, a $0.6^{\circ} \times 0.3^{\circ}$ section at the end of one of the small rectangle components of a hockey stick turned white; because the display background was colored lavender, this change was highly salient. A black dot with $0.4^{\circ}$ diameter served as the probe.

\section{Apparatus}

A Macintosh Quadra 700 was used to display stimuli and record responses. Stimuli were presented on an 11-in. monitor with a resolution of $832 \times 624$ pixels.

\section{Design}

The experiment employed a within-subjects design with four factors (not including stimulus color, which was counterbalanced across participants): orientation (horizontal or vertical displays), occlusion (occluded or nonoccluded hockey stick), cue location (the end of the short rectangle component in any of the four hockey sticks), and cue validity (valid or invalid). Two additional factors determined the location of the probe on invalidly cued trials. Invalid positions could be located in a region of space occupied by a cued hockey stick (withinobject; W) or a noncued hockey stick (between-object; B); we will refer to this factor as object. In addition, invalidly cued probes could appear in positions shared simultaneously by two hockey sticks (shared; S) or occupied solely by a single hockey stick (nonshared; $\mathrm{N}$ ); we will refer to this factor as sharing. The crossing of the latter two factors yields four positions designated WS, BS, WN, and BN. Probes appeared in cued locations on validly cued trials (valid; V) at $1.7^{\circ}$ from fixation. To control for eccentricity effects, both shared probe positions (WS and BS) were the same distance from fixation $\left(1.4^{\circ}\right)$, and both nonshared probe positions were the same distance from fixation $\left(1.7^{\circ}\right.$, the same as the $\mathrm{V}$ position). The WS and BS positions were both $2.0^{\circ}$ from the cued location, and the $\mathrm{WN}$ and $\mathrm{BN}$ positions were both $2.4^{\circ}$ from the cued location.

The experiment was organized into four blocks of trials, two with horizontal displays and two with vertical displays. The participants performed two blocks with the same orientation before they performed two with the other; the order of presentation was counterbalanced across participants. Either an occluded or nonoccluded display was presented on each trial. Cues appeared an equal number of times in each of the four positions in each of the two display types. Cue position and display type were randomized within each block of trials. Probes appeared randomly in one of the five positions associated with their cue with the following constraints: In each block, probes appeared in validly cued positions on $45 \%$ of the trials and in invalidly cued positions on $36 \%$ of the trials $(9 \%$ for each of the four positions WS, BS, WN, and BN). The final 19\% of the trials were catch trials. There were a total of 704 trials in the experiment.

\section{Procedure}

Stimulus presentation and data collection were controlled by PsyScope software (Cohen, MacWhinney, Flatt, \& Provost, 1993). Each trial began with the presentation of a stimulus display. The participants viewed displays from a distance of approximately $100 \mathrm{~cm}$. 
They were instructed to focus their eyes on the central fixation cross. After 1,000 msec, the border surrounding the end of one of the thin rectangles was cued. The border returned to its previous color after $100 \mathrm{msec}$, and the probe dot appeared $50 \mathrm{msec}$ later. The participants were instructed to press a button on a PsyScope-compatible button box as soon as they detected the onset of the probe; the button box recorded RT with millisecond accuracy. Probes remained on the screen until the participants responded or until 1,500 $\mathrm{msec}$ had elapsed. The participants were instructed to withhold responding during catch trials. Trials were separated by an interstimulus interval (ISI) of $700 \mathrm{msec}$.

The participants received an error tone when they responded during a catch trial or at any point before $100 \mathrm{msec}$ had elapsed subsequent to probe onset. The latter was intended to discourage the participants from making anticipatory responses (which were removed subsequently from analysis). Trials during which participants did respond within this time window were subsequently rerun at some random point within the block.

The participants received 16 practice trials at the beginning of the experiment. During the practice session, the experimenter monitored the participants' eye movements and reminded them to maintain fixation of the central cross if they made an accidental saccade. The participants began the experimental trials immediately following the practice session. They were given the opportunity to take a break following each block of trials. The total running time of the experiment was approximately $45 \mathrm{~min}$.

\section{Results}

Percentage of error responses (anticipatory responses or responses during catch trials) was calculated for each participant. Data from the 5 participants whose errors exceeded $10 \%$ were removed from the group data set. Data from the remaining 24 participants ( 3 representatives from each combination of stimulus colors and blocking order) were analyzed further. The mean percentage of error response for these participants was $3.81 \%$.

Validity effect. Each participant's RTs were sorted by orientation, occlusion, and cue validity. Median RTs from each of the resulting cells were submitted to a three-way repeated measures analysis of variance (ANOVA). ${ }^{1}$ Only the main effect of cue validity was significant $[F(1,23)=$ 17.00, $\left.M S_{\mathrm{e}}=362.05, p<.0005\right]$. The participants were faster at responding to probes appearing in cued locations (valid RT $=305.09 \mathrm{msec}, S E=4.06$ ) than they were to those appearing in noncued locations (invalid RT = $316.41 \mathrm{msec}, S E=4.59$ ).

Invalid probe position effects. Each participant's RTs for invalidly cued trials were further sorted by orientation, occlusion, object, and sharing. Median RTs were submitted to a four-way repeated measures ANOVA that included each of these conditions as factors. The main effect of object was significant $\left[F(1,23)=45.45, M S_{\mathrm{e}}=446.14, p<\right.$ .0005], reflecting faster RTs when probes appeared in cued objects (within RT $=309.64 \mathrm{msec}, S E=3.47$ vs. between $\mathrm{RT}=324.17 \mathrm{msec}, S E=3.39)$. The significant main effect of sharing $\left[F(1,23)=9.02, M S_{\mathrm{e}}=249.42, p=.006\right] \mathrm{re}-$ sulted from a decrease in RT for shared as compared with nonshared positions (shared RT $=314.48 \mathrm{msec}, S E=3.54$ vs. nonshared RT $=319.33 \mathrm{msec}, S E=3.39$ ); this difference may be directly attributable to the increased distance from fixation for nonshared positions.
The interaction of object $\times$ orientation was marginally significant $\left[F(1,23)=4.18, M S_{\mathrm{e}}=370.28, p=.053\right]$. This interaction reflects a larger within-object benefit for horizontal (within RT $=307.60 \mathrm{msec}, S E=4.77$ vs. between $\mathrm{RT}=326.15 \mathrm{msec}, S E=4.98)$ as opposed to vertical (within RT $=311.67 \mathrm{msec}, S E=5.07$ vs. between RT = $322.19 \mathrm{msec}, S E=4.62$ ) displays. However, the difference between these two effects was not significant with a Tukey's HSD test $(\alpha=.05)$. Previous cuing studies have found similar orientation-dependent effects on RT (e.g., Kröse \& Julesz, 1989). These orientation effects may reflect any number of factors, including a denser distribution of retinal ganglion cells in the horizontal than in the vertical periphery (Perry \& Cowey, 1985) or a tendency to deploy attention in a horizontal direction during reading. Because there were no other interactions with orientation and the direction of the object trend was the same for both orientations (i.e., both showed a within-object benefit), data were collapsed across orientation for further analysis.

The main objective of this experiment was to determine whether the effect of occlusion on within-object benefits differed depending on which region of the object was probed. Mean RTs are depicted in Figure 3A for nonoccluded displays and in Figure 3B for occluded displays. As is evident, the three-way interaction of object $\times$ sharing $\times$ occlusion was not significant $\left[F(1,23)=1.83, M S_{\mathrm{e}}=\right.$ $318.57, p=.19]$. We also conducted a series of planned comparisons between treatment means of interest; alpha levels were corrected by means of the Holm procedure for multiple comparisons. Within-object RT benefits were significant in both shared and nonshared positions in both nonoccluded and occluded conditions. Condition WS was faster than BS for nonoccluded [ $t(23)=2.45, p<.03]$ and occluded $[t(23)=2.61, p<.02]$ displays, and $\mathrm{WN}$ was faster than $\mathrm{BN}$ for nonoccluded $[t(23)=3.98, p<.0001]$ and occluded $[t(23)=2.42, p<.03]$ displays. Moreover, occlusion had no influence on cuing effects in either shared or nonshared regions of space; there was no significant difference between within-object benefits for occluded and nonoccluded displays in either shared (BS-WS) $[t(23)=$ $-0.12, p>.05]$ or nonshared $(\mathrm{BN}-\mathrm{WN})[t(23)=1.23, p>$ $.05]$ positions.

\section{DISCUSSION}

This experiment yielded several important results. First, we found that participants responded fastest to probes in validly cued locations, demonstrating that cues were effective in drawing attention to the locations in which they appeared (as is typically found in cued probe detection experiments; e.g., Henderson, 1991). Moreover, participants were quicker to detect probes appearing in noncued locations encompassed by the cued object than in those occupied by the noncued object, replicating the original results of Egly et al. (1994). We obtained evidence of this withinobject benefit for the detection of probes in invalidly cued locations under a number of different conditions. In both nonoccluded and occluded displays, probe detection was 


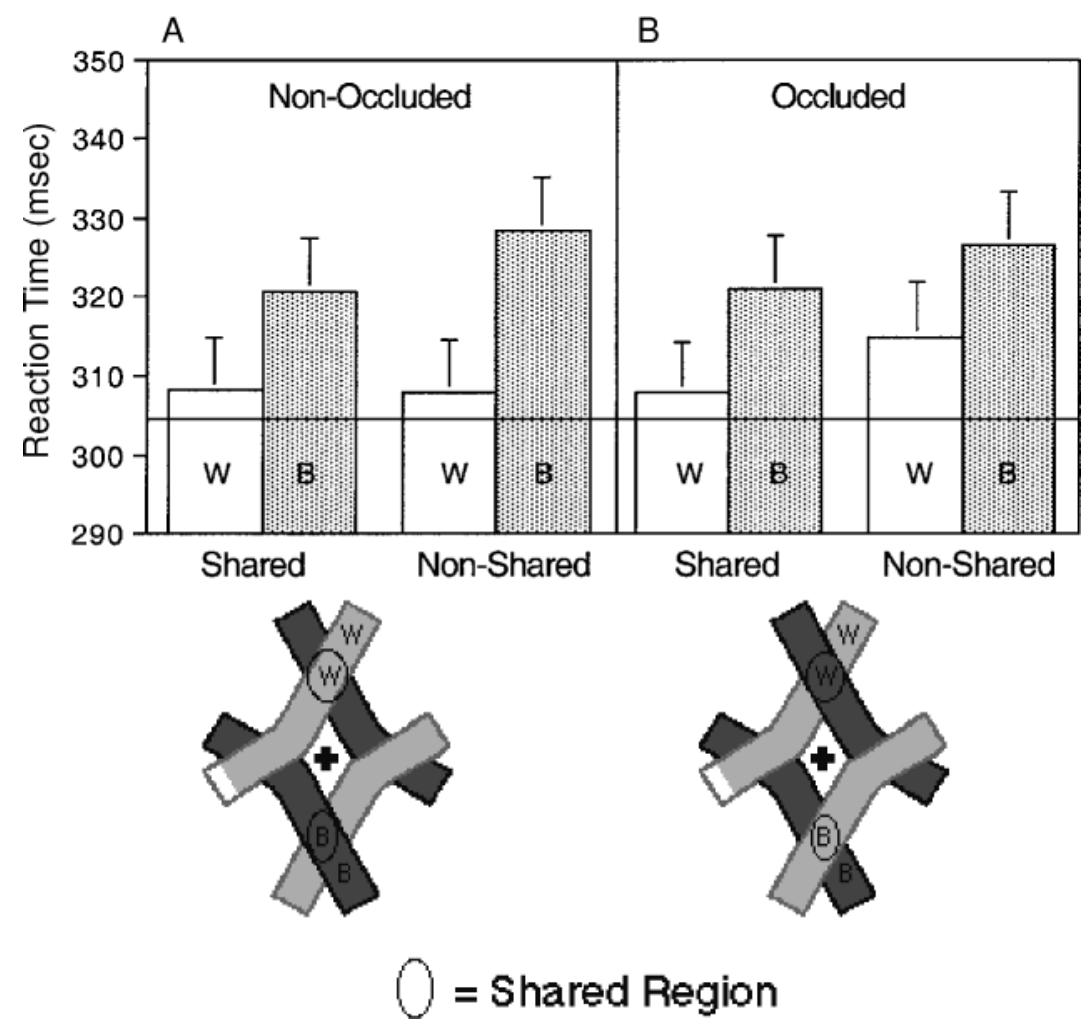

Figure 3. RTs for (A) nonoccluded invalid positions and (B) occluded invalid positions.

faster for within-object as compared with between-object positions in nonshared regions of space. This effect replicates that of Moore et al. (1998) and generalizes their results to nonstereoscopic displays with only pictorial depth cues. Most importantly, we found a within-object benefit for shared positions in both nonoccluded and occluded displays, as hypothesized. ${ }^{2}$

Our finding of faster probe detection in shared regions of occluded displays may seem paradoxical at first. Previously suggested accounts of object-based cuing (e.g., Egly et al., 1994; Vecera, 1994) have attributed the effect to a space-based attention mechanism that selects just those subsets of input that depict cued objects. However, it is unlikely that processes of perceptual organization could have assigned the occluding region of input to the cued object behind it; participants in the experiment as well as 10 additional observers reported that occluded objects continued underneath their occluders, suggesting that the displays did encourage amodal completion. Therefore, in order for a space-based attention mechanism to have selected only those locations associated with a cued occluded hockey stick, it would need to have excluded the occluding region. The within-object benefit for shared positions in occluded displays suggests that it did not.

Nevertheless, as we proposed above, this result is perfectly in keeping with properties attributed to space-based attention. Space-based attention is alleged to perform selection by priming the processing of information in a spe- cific set of locations (e.g., Posner et al., 1980), potentially via feedback from higher-level spatial representations to early representations of visual input (e.g., Farah, 1990; Humphreys \& Riddoch, 1993; Vecera \& Farah, 1994). An occluded object appears to occupy a single set of locations that encompasses both its visible and inferred portions. If the representation of this set of locations serves as the space-based mechanism of selection, space-based attention will prime processing of information within the entire region of space depicted in this representation. Although one can infer that occluded and occluding objects lie at different depths in flat displays, the inference is cognitive and does not yield an actual percept of distinct surfaces. Therefore, the occluding object can appear to subsume the same set of locations as the occluded object in the region where they overlap, and any information appearing within this region will be primed by the spatial representation of the occluded object.

Note that the participants and the 10 additional observers reported that probes presented at WS in occluded displays appeared to lie on the occluding object rather than on the occluded object. None were uncertain about the object on which a probe rested. The stimuli clearly appeared in flat displays, as well. Other than pictorial superposition, there were no cues (e.g., binocular disparity, contextual information from the experimental surroundings, real-world knowledge, etc.) that could have suggested that the occluded and occluding objects appeared at different depths. 
Thus, neither the pictorial interpretation of the scene nor the physical interpretation of the surface were ambiguous; they merely conflicted, and we argue that the participants could maintain such conflicting interpretations simultaneously without interference. One encounters 2-D scenes that portray 3-D spatial relationships fairly often in visual art. Observers generally experience little difficulty understanding the implied 3-D characteristics of the depicted scene, while at the same time accurately assessing the actual structure of the physical environment.

We suggest that the ability to hold simultaneously conflicting interpretations partially reflects a separation (perhaps neuroanatomical; e.g., Ungerleider \& Mishkin, 1982) between representations that depict those relationships defined by perceptual organization and those defined by spatial location. The former distinguish portions of input relating to the attended occluded object from those associated with the occluder, whereas the latter encode the set of locations that the occluded object occupies (which includes its inferred region). Pictorial cues indicating the superposition of the occluder are irrelevant to the spatial representation; thus it provides feedback indiscriminately to all locations it depicts.

Because we obtained evidence of within-object benefit in shared occluded positions, we contend that spacebased attention cannot actually distinguish between superimposed objects that possess only pictorial depth cues (contrary to a proposal suggested by M. I. Posner and mentioned in Duncan, 1984). If space-based attention is limited in this way, only object-based attention (enhanced processing of the representations of specific objects, e.g., Duncan, 1984) could underlie selection among overlapping stimuli (e.g., Behrmann, Zemel, \& Mozer, 1998; Duncan, 1984; Goldsmith, 1998; Vecera \& Farah, 1994). Kramer et al. (1997) demonstrated that probe detection is facilitated in locations previously occupied by overlapping stimuli. Thus, space-based attention may still be allocated during the processing of superimposed objects; however, we propose that it must play only a supporting role during selection.

The results of this study suggest a number of directions for future research. It remains to be determined whether spatial priming spreads to other regions of the occluding object that do not overlap the cued occluded object. Further studies could also explore the degree to which spatial priming transfers to occluded regions when additional cues such as motion or binocular disparity distinguish occluded and occluding surfaces. It would be interesting to examine probe detection in stereoscopic displays with transparent occluders, in order to verify that attention is actually allocated to positions behind the occluder in 3 -D displays. In general, the present experiment has identified a potential limitation to space-based attention, and it demonstrates the need for further investigationsinto the contributions of space- and object-based attentional mechanisms. As this and other studies (e.g., Behrmann et al., 1998; Duncan, 1984; Kramer et al., 1997; Vecera \& Farah, 1994) have already shown, occlusion and superimposi- tion will provide useful tools for disambiguating spaceand object-based components.

\section{REFERENCES}

Atchley, P., Kramer, A. F., Andersen, G. J., \& Theeuwes, J. (1997). Spatial cuing in a stereoscopic display: Evidence for a "depth-aware" attentional focus. Psychonomic Bulletin \& Review, 4, 524-529.

Avrahami, J. (1999). Objects of attention, objects of perception. Perception \& Psychophysics, 61, 1604-1612.

Behrmann, M., \& Haimson, C. (1999). The cognitive neuroscience of visual attention. Current Opinion in Neurobiology, 9, 158-163.

Behrmann, M., Zemel, R. S., \& Mozer, M. C. (1998). Object-based attention and occlusion: Evidence from normal participants and a computational model. Journal of Experimental Psychology: Human Perception \& Performance, 24, 1011-1036.

CAstiello, U., \& Umiltà, C. (1992). Splitting focal attention. Journal of Experimental Psychology: Human Perception \& Performance, 18, 837-848.

CAVE, K. R, \& PAShler, H. (1995). Visual selection mediated by location: Selecting successive visual objects. Perception \& Psychophysics, 57, 421-432.

Cohen, J., MacWhinney, B., Flatt, M., \& Provost, J. (1993). PsyScope: An interactive graphic system for designing and controlling experiments in the psychology laboratory using Macintosh computers. Behavior Research Methods, Instruments, \& Computers, 25, 257-271.

Corbetta, M., Kincade, J. M., Ollinger, J. M., McAvoy, M. P., \& Shulman, G. L. (2000). Voluntary orienting is dissociated from target detection in human posterior parietal cortex. Nature Neuroscience, $\mathbf{3}$, 292-297.

Corbetta, M., Miezin, F., Dobmeyer, S., Shulman, G. L., \& PeterSEN, S. (1991). Selective and divided attention during visual discriminations of shape and color and speed: Functional anatomy by positron emission tomography. Journal of Neuroscience, 11, 2383-2402.

Corbetta, M., Miezin, F., Shulman, G. L., \& Petersen, S. (1993). A PET study of visuospatial attention. Journal of Neuroscience, 13, $1202-1226$.

DAVIS, G., \& Driver, J. (1997a). A functional role for illusory contour spreading in the control of focused attention. Perception, 26, 13971411.

DAVIS, G., \& Driver, J. (1997b). Spreading of visual attention to modally versus amodally completed regions. Psychological Science, 8, 275-281.

Desimone, R., \& Duncan, J. (1995). Neural mechanisms of selective visual attention. Annual Review of Neuroscience, 18, 193-222.

Downing, C. J., \& Pinker, S. (1985). The spatial structure of visual attention. In M. I. Posner \& O. S. M. Marin (Eds.), Attention and performance XI (pp. 171-187). Hillsdale, N.J: Erlbaum.

Duncan, J. (1984). Selective attention and the organization of visual information. Journal of Experimental Psychology: General, 113, 501517.

Egly, R, Driver, J., \& RAfal, R. D. (1994). Shifting visual attention between objects and locations: Evidence from normal and parietal lesion subjects. Journal of Experimental Psychology: General, 113, 501-517.

FARAH, M. J. (1990). Visual agnosia. Cambridge, MA: MIT Press.

Goldsmith, M. (1998). What's in a location? Comparing object-based and space-based models of feature integ ration in visual search. Journal of Experimental Psychology: General, 127, 189-219.

Gottlieb, J. P., Kusunoki, M., \& Goldberg, M. E. (1998). The representation of visual salience in monkey cortex. Nature, 391, 481-484.

He, Z J., \& NaKay Ama, K. (1995). Visual attention to surfaces in threedimensional space. Proceedings of the NationalAcademy of Sciences, 92, 11155-11159.

Henderson, J. M. (1991). Stimulus discrimination following covert attentional orienting to an exogenous cue. Journal of Experimental Psychology: Human Perception \& Performance, 17, 91-106.

Henderson, J. M., \& Macquistan, A. D. (1993). The spatial distribution of attention following an exogenouscue. Perception \& Psychophysics, 53, 221-230. 
Humphreys, G. W., \& RidDOCH, M. J. (1993). Interactions between object and space systems revealed through neuropsychology. In D. E. Meyer \& S. Kornblum (Eds.), Attention and performance XIV (pp. 143-162). Cambridge, MA: MIT Press.

Jolicceur, P., Ullman, S., \& Mackay, M. (1986). Curve tracing: A possible basic operation in the perception of spatial relations. Memory \& Cognition, 14, 129-140.

Kramer, A. F., \& Hahn, S. (1995). Splitting the beam: Distribution of attention over noncontiguous regions of the visual field. Psychological Science, 6, 381-386.

Kramer, A. F., \& JACOBSON, A. (1991). Perceptual organization and focused attention: The role of objects and proximity in visual processing. Perception \& Psychophysics, 50, 267-284.

Kramer, A. F., Weber, T. A., \& Watson, S. E. (1997). Object-based attentional selection: Grouped arrays or spatially invariant representations? Comment on Vecera and Farah (1994). Journal of Experimental Psychology: General, 126, 3-13.

KRöSE, B. J. N., \& Julesz, B. (1989). The control and speed of shifts of attention. Vision Research, 11, 1607-1619.

LAVIE, N., \& DrIVER, J. (1996). On the spatial extent of attention in objectbased visual selection. Perception \& Psychophysics, 58, 1238-1251.

McCormick, P. A., \& Jolicceur, P. (1992). Capturing visual attention and the curve tracing operation. Journal of Experimental Psychology: Human Perception \& Performance, 18, 72-89.

McCormick, P. A., KLein, R. M., \& Johnston, S. (1998). Splitting versus sharing focal attention: Comment on Castiello and Umiltà (1992). Journal of Experimental Psychology: Human Perception \& Performance, 24, 350-357.

Miller, J. O. (1988). A warning about median reaction time. Journal of Experimental Psychology: Human Perception \& Performance, 14, 539-543.

Moore, C. M., Yantis, S., \& VAughan, B. (1998). Object-based visual selection: Evidence from perceptual completion. Psychological Science, 9, 104-110.

Neely, C. A., Dagenbach, D., Thompson, R, \& CARr, T. H. (1998, November). Object-based visual attention: The spread of attention within object and the movement of attention between objects. Paper presented at the annual meeting of the Psychonomic Society, Dallas.

Perry, V. H., \& Cowey, A. (1985). The ganglion cell and cone distribution in the monkey retina: Implications for central magnification factors. Vision Research, 25, 1795-1810.

Phaf, R. H., van der Heijden, A. H. C., \& Hudson, P. T. W. (1990). SLAM: A connectionist model for attention in visual selection tasks. Cognitive Psychology, 22, 273-341.

Posner, M. I., \& Petersen, S. E. (1990). The attention system of the human brain. Annual Review of Neuroscience, 13, 25-42.

Posner, M. I., SNyder, C. R. R., \& Davidson, B. J. (1980). Attention and the detection of signals. Journal of Experimental Psychology: General, 109, 160-174.

Posner, M. I., Walker, J. A., Friedrich, F. J., \& Rafal, R. D. (1984). Effects of parietal injury on covert orienting of attention. Journal of Neuroscience, 4, 1863-1874.

SAIKI, J. (1997, November). Object-based detour of visual attention. Poster session presented at the annual meeting of the Psychonomic Society, Philadelphia.

Steinmetz, M. A., \& Constantinidis, C. (1995). Neurophysiological evidence for a role of posterior parietal cortex in redirecting visual attention. Cerebral Cortex, 5, 448-456.

Ungerleider,L. G., \& Mishin, M. (1982). Two cortical visual systems: Separation of appearance and location of objects. In D. L. Ingle, M. A. Goodale, \& R. J. W. Mansfield (Eds.), Analysis of visual behavior (pp. 549-586). Cambridge, MA: MIT Press.
VeCERA, S. P. (1994). Grouped locations and object-based attention: Comment on Egly, Driver, and Rafal (1994). Journal of Experimental Psychology: General, 123, 316-320.

VeCERA, S. P., \& FARAH, M. J. (1994). Does visual attention select objects or locations? Journal of Experimental Psychology: General, 123, 146-160.

WRIGHT, R. D. (1994). Shifts of visual attention to multiple simultaneous location cues. Canadian Journal of Experimental Psychology, 48, 205-217.

\section{NOTES}

1. Miller (1988) demonstrated that the medians of right-skewed distributions may increasingly overestimate the mean as sample size decreases. Because there were fewer invalid than valid trials in this experiment, an analysis of cell medians could have yielded an exaggerated measure of the true validity effect (invalid RTs could have appeared to be even larger than valid RTs under these conditions). However, we obtained equivalent results when we re-analyzed these data using treatment means instead of medians. Again, only the main effect of cue validity was significant $\left[F(1,23)=19.77, M S_{\mathrm{e}}=381.45, p<.0005\right]$. Participants were still faster at responding to probes appearing in cued locations (valid RT $=306.11 \mathrm{msec}, S E=4.06$ ) than to those appearing in noncued locations (invalid RT $=318.64 \mathrm{msec}, S E=4.74$ ).

2 . We replicated the results of this experiment in a pilot study that utilized nonstereoscopic displays that were more similar to those of Moore et al. (1998). Stimuli were pairs of horizontal or vertical rectangles that appeared above or below a third rectangle oriented perpendicular to the other two; the third occluder rectangle contained a small opening in its center through which the fixation point was visible. As in Moore et al., the occluder rectangle was never cued; however, in our experiments, probes could appear in locations on the occluder that overlapped rectangles behind it.

We obtained a validity effect of $14.68 \mathrm{msec}\left[F(1,15)=57.02, M S_{\mathrm{e}}=\right.$ $120.95, p<.0005]$ (these results were conducted with treatment medians, although analyses with treatment means yielded equivalent results). There was also a main effect of sharing $\left[F(1,23)=9.02, M S_{\mathrm{e}}=249.42\right.$, $p=.006]$, reflecting a decrease in RT for shared as compared with nonshared positions ( shared RT $=314.48 \mathrm{msec}, S E=3.54 \mathrm{vs}$. nonshared RT = $319.33 \mathrm{msec}, S E=3.39$ ); as in the main experiment, this difference may be directly attributable to the increased distance from fixation for nonshared positions. Finally, planned comparisons yielded evidence for within-object benefits (alpha levels were corrected by means of the Holm procedure for multiple comparisons). WS was $12.70 \mathrm{msec}$ faster than BS for nonoccluded displays $[t(15)=5.06, p<.0001]$, and $19.51 \mathrm{msec}$ faster for occluded displays $[t(15)=3.29, p<.005]$. Moreover, WN was $11.48 \mathrm{msec}$ faster than $\mathrm{BN}$ for nonoccluded displays $[t(15)=2.98, p<.01]$ and $8.3 \mathrm{msec}$ faster for occluded displays $[t(15)=2.15, p<.05]$. Importantly, there were no significant differences between within-object benefits for occluded and nonoccluded displays in either nonshared (BN-WN) $[t(15)=0.58, p>.05]$ or shared (BS-WS) $[t(15)=1.25, p>.05]$ positions.

The nonsignificant trend towards a larger within-object benefit for shared positions in occluded displays is somewhat puzzling. It primarily reflects smaller RTs for WS in occluded $(274.5 \mathrm{msec})$ as opposed to nonoccluded ( $280.2 \mathrm{msec})$ displays. Although we have no explanation for this reduction, we did not obtain this result in the main experiment, and we do not feel that it suggests any alternative account of our basic findings.

(Manuscript received January 25, 2000; revision accepted for publication September 21, 2000.) 